\title{
Polls, coalitions and strategic voting under proportional representation
}

Journal of Theoretical Politics 20I4, Vol. 26(3) 442-467 (C)The Author(s) 2013

Reprints and permissions: sagepub.co.uk/journalsPermissions.nav DOI: $10.1177 / 0951629813505722$ jtp.sagepub.com

(SAGE

\section{Michael Herrmann}

Department of Politics and Public Administration, University of Konstanz, Germany

\begin{abstract}
How do polls influence strategic voting under proportional representation? This paper derives a strategic calculus of voting for coalitions that generates testable predictions about the effects of polls on strategic voting in elections involving four or more parties. Incentives of leftist voters to vote for a centrist over a noncentrist party are shown to increase with the difference in expected seats between the prospective right-wing and left-wing coalitions (and vice versa for rightist voters). Centrist voters' incentives to vote for a center-left vs a center-right party are also shown to depend on the relative strengths of the right-wing and left-wing coalitions. Importantly, the strategic voting incentives studied here do not depend on the presence of electoral thresholds or other features of the electoral system. The predictions are tested with survey data from parliamentary elections in Austria and Germany.
\end{abstract}

\section{Keywords}

Coalitional voting; pivot probability; polls; proportional representation; strategic voting

Opinion polls are a common feature of contemporary democracy. During elections, they provide voters with information about the chances of parties and candidates running for office. To many, they may seem fairly innocuous, yet polls enable voters to cast strategic votes. Strategic voting arises if some voters-upon observing the result of a pre-election poll-realize that, instead of opting for their preferred alternative, their vote would have a greater influence on the election's outcome when given to a candidate or party that is not their first choice.

While the impact of polls is well understood in the context of plurality elections (see, e.g., Cox, 1997; Fey, 1997; Forsythe et al., 1993, 1996; Hoffman, 1982; Myatt, 2007; Myerson and Weber, 1993; Palfrey, 1989; Rietz et al., 1998), we still know very little

\section{Corresponding author:}

Michael Herrmann, Department of Politics and Public Administration, University of Konstanz, Postfach 92, D-78457 Konstanz, Germany.

Email: michael.herrmann@uni-konstanz.de 
about their effects on voting in proportional representation (PR) elections. This imbalance is somewhat surprising since the kinds of polls that voters are typically exposed to, i.e. national representative polls, provide more useful information to them in PR elections than in plurality elections. In the latter, a voter can only affect the outcome within her constituency. Polls conducted at the national level do not help the voter much in predicting that outcome. By contrast, polls provide a great deal of information about the election's outcome when votes are tallied nationally, as is typically done in PR elections. In particular, pre-election polls provide voters with information about the likelihood that their vote may be pivotal in creating a seat majority for a prospective coalition government. This generates incentives for strategic voting. Given the availability and the predictive value of polls in PR elections, strikingly little has been done so far to understand their effects on voter decision-making. If voters in PR elections indeed change their vote according to their perception of the election's outcome, then small swings in party support may have a strong influence on short-term voter behavior.

This paper studies the effect of polls on incentives for strategic voting under PR. It derives testable comparative static predictions about the effects of pre-election polls on the party choice of voters facing different coalition outcomes. The framework for the analysis is decision theoretic, focusing on the behavior of an individual voter who cannot coordinate with others in a mass election whose outcome is uncertain. The analysis assumes a multiparty setup involving four or more parties and coalition building along a single policy dimension. Importantly, incentives for strategic voting in this setup do not arise from disproportionalities created by the electoral system (e.g. through representation thresholds). The assumed electoral system is perfectly proportional and strategic behavior is solely driven by majority rule and coalition building in the legislature. The analysis generates straightforward and intuitive empirical predictions which are tested with survey data from the Austrian and German parliamentary elections of 2006 and 2009.

\section{Strategic voting under proportional representation}

The logic of strategic voting is well understood and widely studied in the context of majoritarian elections (see, e.g., Cox, 1984; Fisher, 2004; Herrmann and Pappi, 2008; Niou, 2001; Reed, 1996; Taagepera and Shugart, 1993). Proportional election rules, however, have been rarely subjected to the idea of strategic voting. Since every vote is counted in the allocation of seats, proportional election rules create distortions in outcomes - and, hence, incentives for strategic voting - only through rounding error (Cox and Shugart, 1996). Ignoring rounding error, voters concerned with influencing parties' seat shares face no incentives for strategic voting, unless some legal threshold of representation is introduced that distorts the vote-seat relationship (Slinko and White, 2010). From the outset, voters worried about wasting their vote should thus have little reason to misrepresent their preferences under PR. Yet, this holds mainly with respect to the allocation of seats in parliament. When it comes to decision-making, virtually every parliament in the world applies some form of majority rule. Unless one party happens to win a majority of seats - which rarely occurs in PR elections - parties typically face the need to form coalitions. Majority coalitions are usually very effective in passing legislation and often reduce the influence of noncoalition members on policy-making far below the level implied by 
their seat shares. ${ }^{1}$ Together, majoritarian decision-making and coalition formation thus introduce elements of disproportionality to the allocation of political power that might undermine sincere voting under PR.

In order to vote strategically for a coalition, a voter must find herself in a position where voting for certain parties will increase the chance of a preferred coalition over a less preferred one. This means that potential future governments must be identifiable ex ante. If the deck is stacked in a way that every party could be a member in a whole range of possible coalitions then votes can hardly be directed toward particular outcomes. For example, voting for a party because it is a member of one's preferred coalition will not give the voter much leverage in influencing the final outcome if the same party is also included in other, less preferred, coalitions. What is needed for strategic voting are situations where votes for certain parties clearly distinguish between the outcomes the voter cares about. The multitude of parties typically associated with PR can make identifying the coalitions that might form after an election a difficult task (Downs, 1957).

If one looks at real-world elections, however, one rarely finds situations in which every possible outcome is also a conceivable one. Surprisingly, even in countries with a large number of parties, the set of coalitions which are likely to form after an election is often rather small. The Dutch parliament, for instance, is highly fragmented with typically about eight to ten parties being represented. Yet, most of the time, government formation is confined to only four 'core' parties: the Christian Democrats (CDA), Labour (PvdA), the Liberals (VVD) and the Progressives (D66). Other parties are typically relegated to opposition benches. Indeed, in a systematic analysis of the partisan makeup of coalition governments in 30 post-war democracies, Armstrong and Duch (2010) find that the range of possible coalition outcomes in each country is quite restricted. Coalition formation tends to exhibit high levels of continuity with the same coalitions competing for power over long periods of time.

Potential coalition governments often can be identified before an election takes place (cf. Powell, 2000; Strøm, 1990). One reason is that incumbent parties usually enter the electoral race with the intent to continue government, which, in return, puts pressure on opposition parties to join forces in order to provide a feasible alternative. Opposition parties may also join forces in an attempt to oust an unpopular incumbent government. Studies show that parties often signal their coalition preferences in the run-up to an election or forge pre-electoral coalition agreements (Golder, 2006). Such agreements have a constraining effect on post-election coalition building, increasing the likelihood of the partners to jointly participate in a coalition government (Debus, 2009; Martin and Stevenson, 2001). Another way for voters to identify viable coalitions is through the parties' policy positions: since coalition partners need to agree on future policy decisions, party positions may constrain the formation and duration of coalition governments (Laver and Budge, 1992; Müller and Strøm, 1999, 2003). In particular, ideological closeness has been shown to make parties more likely to become, and stay, partners in a coalition (e.g., Warwick, 1992, 1996). Thus, even in situations where clear signals are largely absent, voters may still evaluate the possibility of particular coalitions forming based on parties' policy positions.

Of course, elections under PR do not always render voters a clearly defined set of outcomes. The predictability of coalition scenarios will often depend on the context of a given election. However, to the extent that coalition-building processes within a country 
exhibit some continuity over time, one would expect voters to learn about the typical outcomes and develop strategies on voting more effectively.

An increasing number of studies now suggest that voting behavior is indeed linked to coalition outcomes. The findings in the literature show, for example, that voters hold fairly clear expectations about which coalitions are likely to form after the election, even in systems with large numbers of parties such as the Netherlands (van Holsteyn and Irwin, 2003) or New Zealand (Bowler et al., 2010). Findings also suggest that a substantial fraction of voters in PR systems do not vote for their preferred party (Abramson et al., 2010; Blais et al., 2006; Shikano et al., 2009); that, on average, voters assign higher ratings to coalitions than to parties (Pappi, 2007); and that coalition preferences influence vote choice beyond party preference (Blais et al., 2006). Based on these findings a number of authors postulate a connection between coalition expectations and voting under PR. Bargsted and Kedar (2009), Bowler et al. (2010), Duch et al. (2010), Linhart (2007), and Meffert and Gschwend (2010) all develop and test arguments suggesting that voters condition their choice of party on the likelihood that the party will enter a governmental coalition. Theoretical underpinnings for these results are provided by Indridason (2011), who studies voting equilibria in which groups of voters strategically coordinate on prospective coalition parties in order to influence a coalition's post-election policy output to their benefit. Relatedly, Austen-Smith and Banks (1988) and Baron and Diermeier (2001) demonstrate the existence of strategic voting equilibria if voters can coordinate in PR elections involving three parties and representation thresholds. ${ }^{2}$

This paper adds to the current state of the literature a rigorous examination of the effects of polls on strategic voting for coalitions. In doing so, it focuses on incentives to influence the set of decisive coalitions, i.e. which coalition wins. The ensuing analysis thus treats possible future coalitions as given and then shows how a voter who wishes to install a preferred coalition but cannot coordinate with others optimally reacts to forecasts about coalitions' strengths in parliament—-something largely neglected by prior studies.

\section{Model}

Consider a single policy dimension and an ordered set of parties labeled $l, c l, c r$ and $r$, which occupy left, center-left, center-right and right positions, respectively. In addition to these four parties, consider one or several 'other' parties, jointly labeled $o$, that might gain representation but will not take part in post-election coalition formation. The positions of these other parties are irrelevant, but we shall assume that some (expressive) voters vote for them, for reasons unrelated to policy outcomes. The results established below do not hinge on the the presence of $o$, but the widespread phenomenon of small specialinterest parties gaining representation in legislatures elected under PR rules suggests that their effect on coalition building should be considered. Technically, the presence of $o$ is similar to assuming a four-party legislature employing a supermajority decision rule: if $o$ wins at least one seat, then whoever wants to control a majority needs more than half of the remaining seats. As we shall see, including $o$ in the parliamentary division of seats changes the number of ways a voter may become pivotal. Appendix $\mathrm{C}$ demonstrates that similar substantive conclusions follow when $o$ is removed from the model. For ease of exposition, assume that $o$ wins only a small fraction of seats. Section 2.3 considers the consequences of increasing $o$ 's seat share and discusses its substantive relevance. 
Given the electoral setup, consider a voter who is a priori certain that no party will win a majority of seats and who expects the outcome of the election to be one of the following two-party majority coalitions: a 'left' coalition $L=\{l, c l\}$, a 'right' coalition $R=\{r, c r\}$ and a 'center' coalition $M=\{c l, c r\}$. In the terminology of the cabinet formation literature, it is assumed that parties form minimal winning, connected coalitions (e.g., de Swaan, 1973). ${ }^{3}$ Let $s_{l}, s_{c l}, s_{c r}, s_{r}$ and $s_{o}$ denote the number of seats of each party and let $s_{L}=s_{l}+s_{c l}, s_{M}=s_{c l}+s_{c r}$ and $s_{R}=s_{c r}+s_{r}$. Let $N=s_{L}+s_{R}+s_{o}$ be the number of seats in parliament.

Assume that the voter considers only which coalition becomes the next government and let $u_{L}, u_{M}$, and $u_{R}$ denote the voter's utility from government by $L, M$ and $R$, respectively. Then one can distinguish three types of voters: leftist voters with preference $u_{L}>u_{M}>u_{R}$, rightist voters with preference $u_{R}>u_{M}>u_{L}$ and centrist voters with preference $u_{M}>u_{R}=u_{L}$. In what follows, we shall focus on leftist and centrist voters. As we shall see, leftist and rightist voters face symmetric incentives and their decision amounts to a binary choice between $l$ and $c l$ in case of a leftist voter and $r$ and $c r$ for a rightist voter. Centrist voters face different incentives and choices, and are treated separately.

To have an effect on the outcome a voter must find herself in a situation where she is decisive. Such a situation arises when one additional vote would turn a minority coalition into a majority coalition. Apart from influencing the set of decisive coalitions we may, in principle, conceive of other ways in which a voter in a proportional election could become decisive. She may, for example, determine which party wins the most seats within a coalition or whether a coalition party wins just another extra seat needed to claim another cabinet portfolio (assuming Gamson's Law). The present analysis sets aside such additional considerations. The reason is that the political impact of a one-seat shift within a given coalition should generally be much smaller than that of putting a coalition into or out of majority status. It thus appears reasonable to assume that a voter considers primarily the effect of her vote on the set of decisive coalitions, as this bears by far the largest consequences in terms of political outcomes. ${ }^{4}$

Table 1 shows all the situations in which a voter would be decisive. There are twelve such instances. For ease of exposition, I abstract away from the details of translating votes into seats. To be clear though, when speaking of a pivotal situation, I envision a distribution of votes such that one additional vote for a certain party results in a change of one seat in favor of the coalition(s) the party is included in. For example, the first two rows describe situations in which $L$ is on the verge of a majority. One vote for either $l$ or $c l$ would turn that coalition into a majority coalition. At the same time $R$ is short of a majority in both situations, while $M$ either commands a majority (second row) or not (first row).

Consider now a leftist voter. Given the pivotal situations, note that voting for either $r$ or $\mathrm{cr}$ as well as abstaining are dominated strategies for her: voting for $r$ can never lead to a better outcome, voting for $\mathrm{cr}$ is at best as good as voting for $\mathrm{cl}$, and abstaining is also never better than either voting for $l$ or $c l$. Thus, the voter faces a binary decision between $l$ and $c l$. In 6 of the 12 situations depicted in Table 1 voting for $c l$ as opposed to $l$ would lead to the same outcome, and the payoff of choosing one or the other party is zero, as shown in the penultimate column. The situations that matter in the voter's decision are those in which votes for $c l$ or $l$ would yield different outcomes and hence nonzero payoffs. 
Table I. Pivotal situations and payoffs of a leftist and a centrist voter.

\begin{tabular}{|c|c|c|c|c|c|c|}
\hline \multirow{2}{*}{$\frac{\text { No. }}{\# 1}$} & \multicolumn{3}{|c|}{ Pivotal situation } & \multirow{2}{*}{$\begin{array}{c}\begin{array}{c}\text { Pivot } \\
\text { probability }\end{array} \\
p_{1}\end{array}$} & \multirow{2}{*}{$\begin{array}{c}\begin{array}{c}\text { Leftist voter } \\
\text { payoff: } u(c l)-u(l) \\
0\end{array}\end{array}$} & \multirow{2}{*}{$\begin{array}{c}\text { Centrist voter } \\
\text { payoff: } u(c l)-u(c r \\
-\left(\frac{u_{L}+u_{M}}{2}-u_{L}\right)\end{array}$} \\
\hline & $s_{L}=\frac{N}{2}$ & $s_{M}<\frac{N}{2}$ & $s_{R}<\frac{N}{2}$ & & & \\
\hline$\# 2$ & $s_{L}=\frac{N}{2}$ & $s_{M}>\frac{N}{2}$ & $s_{R}<\frac{N}{2}$ & $p_{2}$ & 0 & $-\left(u_{M}-\frac{u_{L}+u_{M}}{2}\right)$ \\
\hline$\# 3$ & $s_{L}<\frac{N}{2}$ & $s_{M}<\frac{N}{2}$ & $s_{R}=\frac{N}{2}$ & $p_{3}$ & 0 & $\frac{u_{M}+u_{R}}{2}-u_{R}$ \\
\hline$\# 4$ & $s_{L}<\frac{N}{2}$ & $s_{M}>\frac{N}{2}$ & $s_{R}=\frac{N}{2}$ & $p_{4}$ & 0 & $u_{M}-\frac{u_{M}+u_{R}}{2}$ \\
\hline \#5 & $s_{L}<\frac{N}{2}$ & $s_{M}=\frac{N}{2}$ & $s_{R}<\frac{N}{2}$ & $p_{5}$ & $\pm\left(\frac{u_{M}}{2}-\frac{u_{L}+u_{R}}{4}\right)$ & 0 \\
\hline \#6 & $s_{L}<\frac{N}{2}$ & $s_{M}=\frac{N}{2}$ & $s_{R}>\frac{N}{2}$ & $p_{6}$ & $\frac{u_{M}+u_{R}}{2}-u_{R}$ & 0 \\
\hline$\# 7$ & $s_{L}<\frac{N}{2}$ & \multicolumn{2}{|c|}{$s_{M}=s_{R}=\frac{N}{2}$} & $p_{7}$ & $\pm\left(\frac{u_{M}}{2}-\frac{u_{L}+u_{R}}{4}\right)$ & $u_{M}-\frac{u_{M}+u_{R}}{2}$ \\
\hline$\# 8$ & $s_{L}>\frac{N}{2}$ & $s_{M}=\frac{N}{2}$ & $s_{R}<\frac{N}{2}$ & $p_{8}$ & $-\left(u_{L}-\frac{u_{L}+u_{M}}{2}\right)$ & 0 \\
\hline \#9 & \multicolumn{2}{|c|}{$s_{L}=s_{M}=\frac{N}{2}$} & $s_{R}<\frac{N}{2}$ & $p_{9}$ & $-\left(u_{L}-\frac{u_{L}+u_{M}}{2}\right)$ & $-\left(u_{M}-\frac{u_{L}+u_{M}}{2}\right)$ \\
\hline$\# 10$ & \multicolumn{2}{|c|}{$s_{L}=s_{R}=\frac{N}{2}$} & $s_{M}<\frac{N}{2}$ & $p_{10}$ & 0 & b \\
\hline$\#$ \#I & \multicolumn{2}{|c|}{$s_{L}=s_{R}=\frac{N}{2}$} & $s_{M}>\frac{N}{2}$ & $p_{11}$ & 0 & b \\
\hline$\# 12$ & \multicolumn{3}{|c|}{$s_{L}=s_{M}=s_{R}=\frac{N}{2}$} & $p_{12}$ & $-\left(u_{L}-\frac{u_{L}+u_{M}}{2}\right)$ & 0 \\
\hline
\end{tabular}

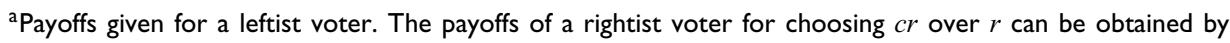
exchanging $s_{L}$ and $s_{R}$ in each pivotal situation and by exchanging $u_{L}$ and $u_{R}$ in each payoff expression.

${ }^{b}$ In situations 10 and $\mathrm{II}$ a centrist voter is better off abstaining than casting a vote for either $c l$ or $c r$. Abstention is beneficial in situation 10 because the voter prefers any three-party coalition, which always involves $M$, to either $L$ or $R$.

In determining these payoffs, note that in cases where a decisive vote would change the result from a single majority to simultaneous majorities for two coalitions, the final policy outcome is treated as uncertain from the perspective of the voter and, hence, voter utility is averaged across both potential outcomes. ${ }^{5}$

Inspecting a leftist voter's payoffs, one can see that a $c l$ vote is beneficial in situation 6 while a left vote is beneficial in situations 8,9 and 12. In situations 5 and 7, the voter's payoff depends on how she rates coalition $M$ relative to the other two coalitions. To see why, note that a voter can either install a centrist coalition by voting for $\mathrm{cl}$, or she might vote for $l$, in which case no coalition would have enough seats to form a government. Based on the assumption of minimal winning, connected coalitions, it is assumed that, if the voter chooses $l$, the two centrist parties will form a three-party coalition with either $l$ or $r$, both with equal probability. The voter's utility from a three-party government by $l, c l$ and $\mathrm{cr}$ is assumed to be between $u_{L}$ and $u_{M}$, and her utility from a three-party government by $\mathrm{cl}, \mathrm{cr}$ and $r$ is assumed to be between $u_{M}$ and $u_{R}$. For convenience, the utility from each three-party government is defined as the simple average of the corresponding two-party government utilities, but this assumption does not affect the substantive conclusions that follow. The payoff from a $c l$ vote in situations 5 and 7 then equals $u_{M}-\left(\left(u_{L}+u_{M}\right) / 2+\right.$ $\left.\left(u_{M}+u_{R}\right) / 2\right) / 2$, which can be simplified to yield the expressions in Table $1 .{ }^{6}$ Note that the payoff from a $c l$ vote in situations 5 and 7 is positive for voters with $u_{M}>\left(u_{L}+u_{R}\right) / 2$, negative for voters with $u_{M}<\left(u_{L}+u_{R}\right) / 2$, and zero otherwise. 
Given the pivotal situations and voter payoffs we can now establish the optimal voting criterion for leftist voters. A symmetric argument holds for rightist voters.

Proposition 2.1. For a leftist voter let $u_{L}=1$ and $u_{R}=0$, then there exists a threshold $\tau$ and a strategic incentive $\eta$ such that the voter chooses party cl over party $l$ if and only if $\eta>\tau$, where $\tau=\frac{1-u_{M}}{u_{M}}$ and

$$
\eta= \begin{cases}\frac{\left(p_{5}+p_{7}\right)\left(1-\frac{1}{2 u_{M}}\right)+p_{6}}{p_{8}+p_{9}+p_{12}} & \text { if } u_{M}>\frac{1}{2} \\ \frac{p_{6}}{p_{8}+p_{9}+p_{12}} & \text { if } u_{M}=\frac{1}{2} \\ \frac{p_{6}}{\left(p_{5}+p_{7}\right) \frac{1-2 u_{M}}{2-2 u_{M}}+p_{8}+p_{9}+p_{12}} & \text { if } u_{M}<\frac{1}{2}\end{cases}
$$

It follows from Proposition 2.1 that a stronger preference for $M$ lowers the voter's threshold and thus increases her likelihood of choosing $\mathrm{cl}$. Since the strategic incentive is conditional on $u_{M}$, it also follows that a stronger preference for $M$ affects the voter's decision by, ceteris paribus, raising her strategic incentive to choose $c l$. Holding constant the voter's preference for $M$, note that the incentive to cast a vote for $c l$ over $l$ is strictly increasing in $p_{6}$ and decreasing in $p_{8}, p_{9}$ and $p_{12}$. In other words, the more likely the election is going to lead to situation 6 , the more likely a leftist voter is to vote for $\mathrm{cl}$; the more likely it is going to lead to situations 8,9 or 12 , the more likely she is to vote for $l$. This is where polls come into play.

Consider now a centrist voter. Obviously, voting for a noncentrist party is a dominated strategy for her. However, as shown in the last column of Table 1, in 6 out of the 12 pivotal situations the payoff to the voter of choosing $\mathrm{cl}$ over $\mathrm{cr}$ is nonzero. Note that in determining the payoffs in situations 1 and 3, it is again assumed that if the voter chooses not to install a left (resp. right) coalition, the two centrist parties will form a coalition with either $l$ or $r$. As above, the voter's utility from such an outcome is taken to be $\left(\left(u_{L}+u_{M}\right) / 2+\left(u_{M}+u_{R}\right) / 2\right) / 2$, which means that a centrist voter is assumed to prefer each three-party coalition to a government by either $L$ or $R$. The expressions given in Table 1 result after noting that, for centrists, $u_{R}=u_{L}$. Furthermore, we can see from Table 1 that there are two situations in which a centrist would be better off abstaining than choosing either of the centrist parties: in situation 11 a vote for a centrist party would destroy an existing unique majority for the preferred coalition; in situation 10 it would create a unique majority for a disliked coalition where else parties would be forced to form either a right-leaning or a left-leaning three-party coalition. ${ }^{7}$

Given her three possible choices, Proposition 2.2 establishes the optimal voting criterion for a centrist voter.

Proposition 2.2. For a centrist voter let $u_{M}=1$ and $u_{L}=u_{R}=0$.

(a) There exists a strategic incentive $v$ such that the voter chooses party cl over party $\mathrm{cr}$ if and only if $v>1$, where $v=\frac{p_{3}+p_{4}+p_{7}}{p_{1}+p_{2}+p_{9}}$.

(b) $v$ is the optimal voting criterion if and only if $\iota \leq 1$, where $\iota=\frac{p_{10}+p_{11}}{p_{5}+p_{6}+p_{7}+p_{8}+p_{9}}$. For $\iota>1$, the voter's optimal choice is to abstain.

Inspecting part (b) of Proposition 2.2 notice that the denominator in $\iota$ is roughly equal to $\operatorname{Pr}\left(s_{M}=N / 2\right)$ while the numerator roughly equals $\operatorname{Pr}\left(s_{L}=s_{R}=N / 2\right)$. A centrist voter 
should therefore abstain whenever the election is more likely to lead to the outcome of $L$ and $R$ splitting the parliament than $M$ winning half the seats. Since the former requires that $o$ wins no seats at all (splitting the parliament implies that half the seats must go to $l$ and $c l$ with the other half going to $c r$ and $r$ ) it follows that abstaining will be optimal only under very particular circumstances. The decision criterion in part (a), however, is based on two sets of completely symmetric situations: 3, 4, and 7 vs 1, 2, and 9. As we shall see, this makes the choice between $c l$ and $c r$ a fairly straightforward task.

\section{I. The impact of polls}

In what follows, we shall examine how the strategic incentives from Propositions 2.1 and 2.2 change in response to changes in the expected seat shares of $L, R, M$ and $o$. To the individual voter, the probabilities of the different pivotal situations occurring depend on the expected election outcome. If polls indicated a change in the expected outcome (e.g. if $R$ 's expected seat share waned) this would alter the probabilities of the different pivotal situations and thus change the voter's incentives for strategic voting. The central prediction established in this section is that the incentive of leftist voters for choosing between $\mathrm{cl}$ and $l$ and the incentive of centrist voters for choosing between $\mathrm{cl}$ and $\mathrm{cr}$ both depend on a single quantity that can be easily extracted from public opinion polls: the difference in expected seat shares of $L$ and $R$.

Assume that the outcome of the election, i.e. the number of seats of each party in parliament, is a multinomial random variable with parameter vector $\pi$. Each element $\pi_{j}$ in this vector denotes the probability that a seat in parliament will go to party $j$. Since, in a highly proportional system, these probabilities should be directly related to parties' expected vote shares (i.e. to the fraction of voters who are likely to support each party in the election), pre-election polls essentially provide voters with information about $\pi$. Lemma A.1, which can be found in Appendix A, states the multinomial formulas for the pivot probabilities. Using Lemma A.1, it is possible to determine the strategic incentive for arbitrary voter expectations about parties' seat shares in parliament.

To establish our main comparative static prediction, consider a situation in which expected seat shares are $\pi_{l}=0.15, \pi_{c l}=0.3, \pi_{c r}=0.3, \pi_{r}=0.15$ and $\pi_{o}=0.1$. Now, let us examine the movement in the strategic incentives of leftist and centrist voters, when expected seat shares of $L, M, R$ and $o$ are altered in a ceteris paribus manner. Let $\pi_{L}=\pi_{l}+\pi_{c l}, \pi_{M}=\pi_{c l}+\pi_{c r}, \pi_{R}=\pi_{c r}+\pi_{r}$, denote the expected seat shares of $L, M$ and $R$, and let $\delta=\pi_{R}-\pi_{L}$ denote the difference in $R$ and $L$ 's expected seat shares. Figure 1 depicts the model's key predictions. Note that, for ease of illustration, each strategic incentive variable and voters' threshold values were log transformed. For the voter's decision problem this step is of course immaterial.

Consider a leftist voter. The top-left panel in Figure 1 shows the incentive of a leftist voter depending on her expectation of the relative strength of $R$ (the disliked outcome) vs $L$ (the preferred outcome), and on her relative preference for $M$. The initial setup described above corresponds to a zero difference between $L$ and $R$ 's expected seat shares. As can be seen, for all three types of voters the incentive to vote for $c l$ strictly increases in the difference between $R$ and $L .{ }^{8}$ From the other two panels in the top row of Figure 1 we see that, irrespective of the voter's preference for $M$, strategic voting does not depend on $M$ or $o$ 's expected seat shares. Although the strategic incentive changes with respect 

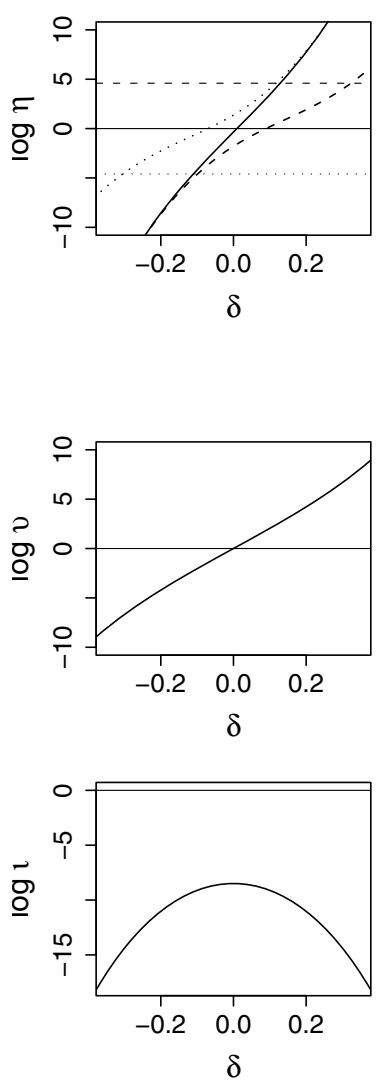

Leftist voter

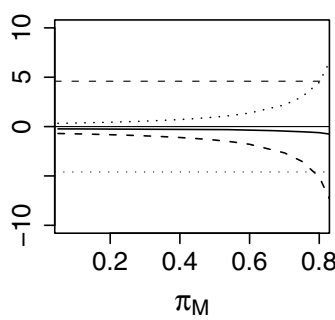

Centrist voter
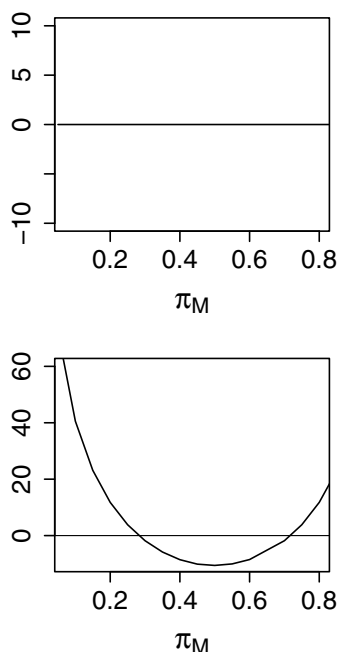
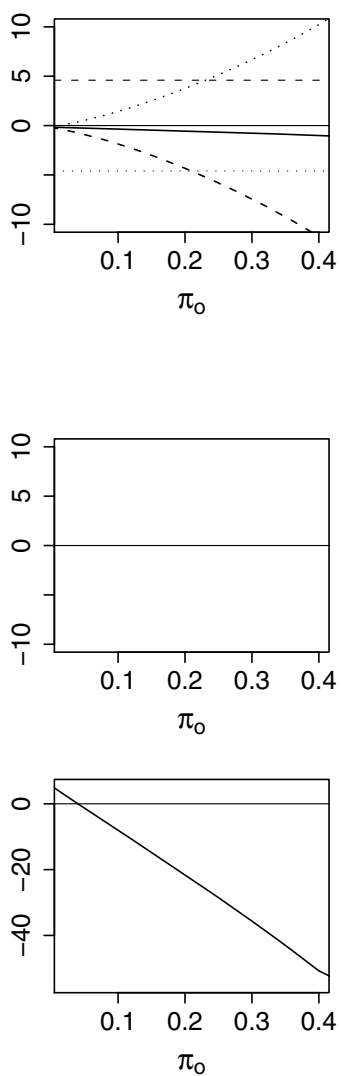

Figure I. The strategic incentive of leftist and centrist voters depending on the expected seat shares of $L, R, M$ and $o$. For ease of display, each incentive variable and its associated threshold value have been log transformed. In the left panel the $x$-axis indicates the difference between the expected seat shares of $L$ and $R$, i.e. $\delta=\left(\pi_{r}+\pi_{c r}\right)-\left(\pi_{c l}+\pi_{l}\right)$. In the middle panel the $x$-axis indicates the expected seat share for $M$, i.e. $\pi_{M}=\pi_{c l}+\pi_{c r}$. Horizontal lines drawn in each of the upper three panels represent the log transformed threshold levels, $\tau$, of a leftist voter with $u_{M}=0.01$ (dashed), $u_{M}=0.5$ (continuous), and $u_{M}=0.99$ (dotted), respectively. Horizontal lines drawn at zero in the remaining panels indicate a centrist voter's log transformed threshold.

to $\pi_{M}$ or $\pi_{o}$, it never crosses the threshold for a given type of voter, inducing no change in behavior.

Why does this result obtain? Looking back to Table 1, we see that in situation 6 , in which a centrist vote would always be beneficial, coalition $R$ wins more seats than $L$. In situations 8,9 and 12, in which a noncentrist vote would be optimal, $R$ always wins fewer seats than $L$. Thus, situation 6 should be more likely than 8,9 and 12 whenever 
coalition $R$ is expected ahead of $L$ (and vice versa), and this is essentially what is driving the result. This is most obvious for voters with $u_{M}=0$. For the other two types of voters, the decision also depends on the likelihood of situations 5 and 7, but the likelihood of situation 5 does not vary systematically with expected seat shares for $L$ and $R$. The likelihood of situation 7 does vary with the expected seat shares for $L$ and $R$, but it does not alter the strategic incentive very much because the probability of situation 7 is small compared to the probabilities of situations 6 or 8 (the latter two probabilities are the main driving forces behind the result). On the other hand, $M$ and $o$ 's expected seats only influence the absolute probability of the situations that are relevant to a leftist voter. For example, the closer $M$ 's expected seat share is to 0.5 , the greater the likelihood of any of these pivotal situations. The relative likelihood of situation 6 to situations 8,9 and 12 , however, is not affected by $M$ or $o$ 's expected seat shares.

Turning to a centrist voter's decision problem, we see that $v$ (the incentive to choose $c l$ over $c r$ ) likewise depends on the difference in expected seat shares for $L$ and $R$ for much the same reason as in the leftist voter's case: in situations 3, 4 and 7, coalition $L$ wins less seats than coalition $R$ while it wins more seats than $R$ in situations 1, 2 and 9 . The difference in expected seat shares for $L$ and $R$ also affects $\iota$ (the voter's incentive to abstain) which decreases as we move away from a situation where $L$ and $R$ are expected to split the parliament. The reason the incentive stays below the abstention threshold is that $o$ 's expected seats are kept constant at 0.1 . Thus, even in the case of zero expected difference between $L$ and $R$ (the initial setup) both coalitions are expected to win less than half the seats - enough to keep the incentive strictly negative in this example. In light of our discussion of Proposition 2.2, it comes as no surprise to find that a centrist voter's incentive to abstain also responds to changes in expected seats of $M$ and $o$. Specifically, $\iota$ increases as we move away from a situation where $M$ is expected to win half the seats and it decreases in the number of expected seats for $o .^{9}$

To show that the relationships illustrated above are likely to hold across the entire range of poll results a voter might be confronted with, I employ Monte Carlo simulations. The idea of the simulation is to randomly generate arbitrary voter expectations about parties' seat shares, which may then be used to see whether the above relationships hold true on average. ${ }^{10}$ The procedure is as follows:

1. Simulate an expected distribution of seats by taking a random draw from a uniform Dirichlet distribution with five outcome categories, $\pi_{l}, \pi_{c l}, \pi_{c r}, \pi_{r}$ and $\pi_{o}$, subject to the constraint that each seat share does not exceed 0.5 (i.e. accept a draw, if the values in all outcome categories are below 0.5, otherwise take a new draw).

2. Use Propositions 2.1 and 2.2 together with Lemma A.1 to evaluate $\eta, v$ and $\iota$ based on $\pi$ and $N=100$ (for a leftist voter let $u_{M}$ range from 0 to 1 ).

3. Repeat.

Figure 2 summarizes the main results of the Monte Carlo analysis. As can be seen, leftist and centrist voters' decision problems (with respect to party choice), on average, exhibit monotone comparative statics in $\delta$ but not in the other two variables. Changes in $M$ or $o$ 's standing in the polls show no uniform effects on strategic voting but they affect a centrist voter's decision to abstain. The latter exhibits monotone comparative statics in functions of $\delta, \pi_{M}$ and $\pi_{o}$, on average. The behavioral import of these predictions is, however, limited by the fact that, despite systematic variation, the incentive to abstain becomes 
positive only in particular cases. Inspecting the three lower panels in Figure 2 one can see that neither of the three variables alone is sufficient in determining whether or not the voter will abstain. Clearly, for high values of $|\delta|$ or values of $\pi_{M}$ roughly between 0.3 and 0.7 the voter will not abstain, irrespective of $\pi_{o}$. But low values of $|\delta|$ alone do not guarantee a positive incentive to abstain. In fact, most of the time the voter would still refrain from doing so. Likewise, unless $M$ polls close to either 0 or $100 \%$, the incentive to abstain may still be negative even if $\pi_{M}$ is far from 0.5 . Thus, predictions about abstention should not be made on the basis of $|\delta|, \pi_{M}$ or $\pi_{o}$ alone. While lowering $|\delta|$, for instance, increases the incentive to abstain, in most situations we would nevertheless predict that a centrist voter should choose one of the two centrist parties.

\subsection{Aggregate outcomes}

Based on the comparative static results we may conjecture how strategic voting would affect electoral outcomes as a whole. Staying within the decision theoretic framework, assume that voters truthfully reveal their (strategic) choices over the course of repeated pre-election polls. Assume further that, in the first round of polling, centrist and noncentrist voters simply randomize between their two party choices.

Suppose now the initial situation was tilted toward the left coalition. ${ }^{11}$ Some leftist voters would then strategically desert $c l$ in favor of $l$, and some rightist voters would migrate from $r$ to $\mathrm{cr}$. Centrist voters, by contrast, would face an incentive to vote for $\mathrm{cr} .^{12}$ As a result, the expected division of seats between $L$ and $R$ would become more equal and thus induce some leftist and rightist voters to reverse their decisions after the next round of polling. Remarkably, simply by reacting to polls, centrist voters would put a limit on the extent to which noncentrist voters will strategically migrate between centrist and noncentrist parties. ${ }^{13}$ Strategic voters would keep each other in check even if they do not anticipate each others' behaviors.

The stability of this sequence of actions would depend on whether centrist voters' switching to $\mathrm{cr}$ partly offsets, completely offsets or reverses the imbalance between $L$ and $R$ 's electoral prospects. Partly offsetting the imbalance would lead some, but not all, noncentrist voters to reverse their decisions; but nothing else would change after that since centrists' incentives to vote for $c r$ would remain positive. The result would be a steady state in which all parties retain positive vote shares. No steady state but a steady sequence of states would result if centrist voters completely offset or reverse the margin between $L$ and $R$. In the former, once balance was achieved, centrist voters would become indifferent to the two centrist parties, restore some of the initial imbalance in the next round of polls, and then switch back and forth between voting for $\mathrm{cr}$ and voting randomly in subsequent rounds. Likewise, in the latter case, centrist voters would subsequently switch back and forth between voting for $\mathrm{cr}$ and $\mathrm{cl}$, thereby inducing some leftist and rightist voters to constantly reverse their decisions.

What this informal discussion suggests is that, in the longer run, we would not expect strategic voting for coalitions under PR to lead to the kind of lopsided or heavily biased election results that strategic voting models predict for other contexts, where some parties win all the votes, while all remaining parties get devastated (see, e.g., Fey, 1997; De Sinopoli and Iannantuoni, 2007). Likewise, strategic voting should not lead to more 

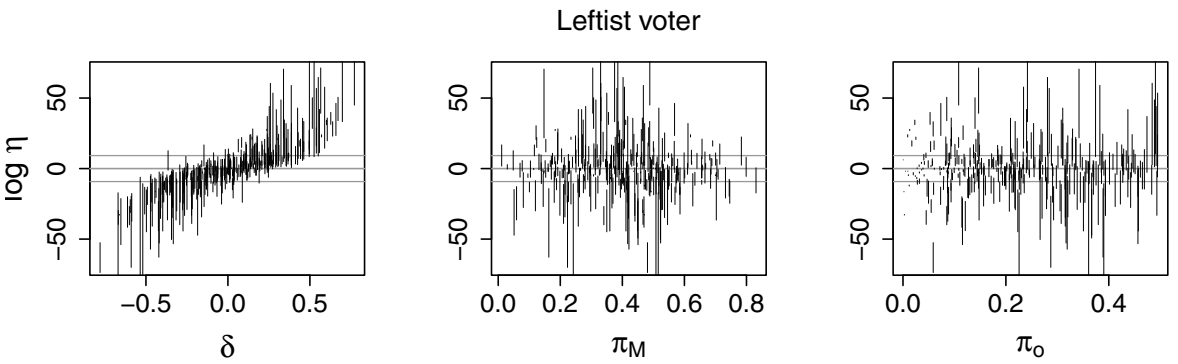

Centrist voter
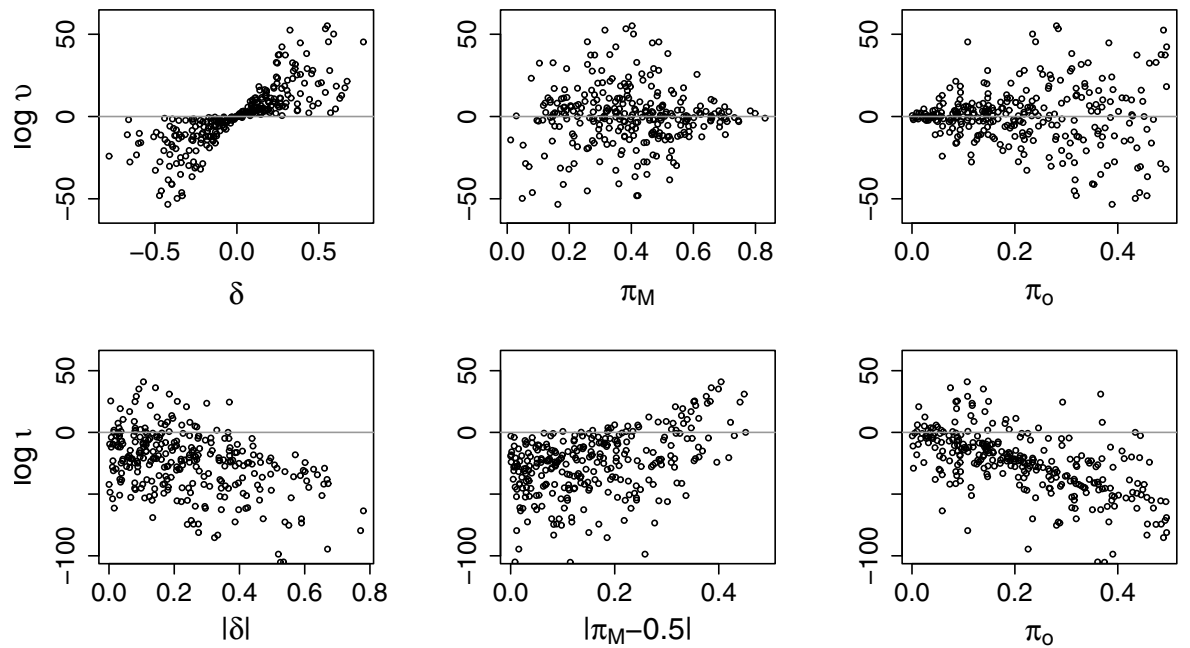

Figure 2. The strategic incentive of leftist and centrist voters depending on $\delta=\pi_{R}-\pi_{L}, \pi_{M}$ and $\pi_{o}$. For ease of display, each incentive variable and its associated threshold value have been log transformed. For the leftist voter, each vertical line in one of the panels represents the entire range of possible values of the strategic incentive over different values of $u_{M}$. The lower end of each line represents the strategic incentive for $u_{M}=0$; the upper end represents the strategic incentive for $u_{M}=1$. Reference lines indicate log transformed threshold levels, $\tau$, of a leftist voter with (top to bottom) $u_{M}=0.0001, u_{M}=0.5$ and $u_{M}=0.9999$, respectively. The centrist voter's log transformed threshold is indicated by a reference line at zero. Predictions based on 300 simulation runs.

or less ideological polarization in the distribution of votes. Strategic voting at the microlevel may produce aggregate outcomes that look quite 'normal' (i.e. resembling outcomes in which everybody expressively voted their policy preference), which should make it hard to infer its presence simply by looking at election outcomes. 


\subsection{Scope and limits of predictions}

Given the simplicity of the electoral setup, one might wonder whether the predictions derived above also apply to situations involving a different number of parties and alternative forms of coalition building. First, as shown in Appendix C, if we assume that other (noncoalition) parties will not gain representation in parliament, the incentive of centrist voters to choose between the two centrist parties disappears. However, the other comparative static predictions established above remain substantively unchanged if noncoalition parties are excluded.

Second, increasing the number of noncoalition parties that enter parliament, i.e. increasing $s_{o}$, makes a majority for any two-party coalition of the remaining parties less likely. Since, in countries where noncoalition parties obtain a large number of seats (e.g. in Norway or Israel), coalitions often involve more than two parties, let us briefly consider what would happen if we assumed that any two-party coalition was unlikely to win enough seats to form a government. A voter expecting a situation where parties must form three-way coalitions faces two possible outcomes: a coalition by $l, c l$ and $c r$ and a coalition by $c l, c r$ and $r$. A leftist voter would prefer the former over the latter, and vice versa for a rightist voter. A centrist voter would be indifferent between both outcomes and, hence, face no incentive to vote strategically any more. Given the two possible coalitions, the only way for a leftist voter to achieve a better result is by voting for $l$ (and for a rightist voter by voting for $r$ ). Choosing $\mathrm{cl}$ (resp. $\mathrm{cr}$ if the voter is a rightist) would always amount to supporting both outcomes. Thus, voting for a centrist party is a dominated strategy. To see that this is true, we can again work our way through the relevant pivotal situations. There are five such situations: both three-way coalitions could tie at $N / 2$; the left threeway coalition could finish at $N / 2$ and the other above; the right three-way coalition could finish at $N / 2$ and the other above; the left three-way coalition could finish at $N / 2$ and the other below; and the right three-way coalition could finish at $N / 2$ and the other below. In each situation, a leftist voter would be at least as good or better off voting for $l$ than voting for $\mathrm{Cl}^{14}$ With three-party coalitions becoming increasingly likely, the incentive to choose a centrist party disappears. Thus, higher expected seat shares for noncoalition parties should lead to more voting for noncentrist coalition parties. Since noncoalition parties in real elections are themselves often noncentrist or extremist parties, increasing (exogeneous) support for those parties should work against the most centrist parties-but not necessarily against their noncentrist coalition partners.

Third, the current analysis assumes that parties form minimal winning, connected coalitions. As such, its predictions are confined to cases that meet these assumptions. While this is a restriction of the current framework, it should be noted that extensions to other types of cases seem possible. For instance, one should be able to conduct a similar analysis assuming that parties form nonconnected coalitions. Suppose, for example, $l$ would enter a coalition with $c r$ instead of $c l$. This would change the relevant pivotal situations and possible voter types; however, one would still be able to work out voters' strategic incentives in essentially the same way as before. Another way to extend the current analysis would be to allow for the formation of minority or surplus governments. For example, one could assume that the largest party will form a minority government if it controls the median legislator (cf. Laver and Schofield, 1998); if not, a majority coalition of the parties to its right (resp. left) will form. To accommodate surplus majorities, a 
government coalition might be assumed to require more than a bare majority of seats in order to win. The general point to take away from this is that strategic voting incentives arise whenever post-election coalition building provides for situations in which an additional seat for one party would change the set of decisive coalitions. While the current model assumes that parties form minimal winning, connected coalitions, other assumptions about the government formation process are likely to carry implications for voter decision-making as well.

\section{Evidence}

The comparative static analysis carried out in Section 2.1 implies the following testable hypotheses: noncentrist voters should be more likely to choose a centrist over a noncentrist prospective coalition party (a) the higher $u_{M}$ and (b) the higher $\delta$ are (where $\delta$ is taken to be the expected difference in strength between a leftist, resp. a rightist, voter's disliked and preferred coalition) and (c) the effect of $\delta$ should increase with $u_{M}$ (see also the discussion of Proposition 2.1). Centrist voters should be more likely (d) to choose a center-left over a center-right party the higher $\delta$ is (where $\delta$ is taken to be the expected difference in strength between the right and left coalitions) and (e) to abstain rather than to vote for a centrist party if $\delta$ is close to 0 and $\pi_{M}$ is at least 20 percentage points away from $50 \%{ }^{15}$

Ideally, one would test these predictions in a controlled experiment. For expository purposes, I shall exploit cross-sectional variation in voters' perceptions of poll results using survey data on voter behavior in the 2006 Austrian parliamentary election and the 2009 German federal election. Austria and Germany both employ PR systems, and governments in these countries typically consist of minimal winning, connected coalitions. The coalitions most likely to emerge from the 2006 Austrian national election were a left-wing coalition by the Greens and the SPÖ, a right-wing coalition by the ÖVP and the FPÖ, and a grand coalition by the SPÖ and the ÖVP. ${ }^{16}$ In Germany, the three possible options for future government were a left-wing coalition by the Greens and the SPD, a right-wing coalition by the CDU and the FDP, and a grand coalition by the CDU and the SPD (which was the incumbent government at the time). The Austrian extreme right BZÖ and the German socialist Left party, which both gained representation, were rejected beforehand as potential coalition partners by the other parties. Coalition governments were formed by the SPÖ and the ÖVP in Austria and by the CDU and the FDP in Germany.

I employ data from two pre-election surveys which, unlike standard surveys, feature a set of questions asking for respondents' expectations about the likelihoods of different coalitions winning a majority of seats after the election (for details about the surveys and question wordings see Appendix D). I shall focus on hypotheses (a)-(d). Hypothesis (e) is left to future study as it requires more precise manipulation of voter expectations than the current data provide. Voter types were inferred from respondents' ideological selfplacements on standard 11-point left-right scales. Voters at position 6 were treated as centrists, positions 1-5 were coded as leftist and positions 7-11 as rightist. The dependent variable scores 1 for noncentrist voters if they chose a centrist party (e.g. leftists who chose the SPÖ, resp. the SPD) and 0 if they chose a noncentrist party (e.g. leftists who chose the Greens). It also scores 1 for centrist voters if they chose the center-left party and 
0 if they choose the center-right party (i.e. the ÖVP or the CDU). A noncentrist voter's preference for a centrist coalition, $u_{M}$, was measured by the voter's distance to the center of the ideological scale. This measure scores 0 for voters at the extremes and 4 for voters to the left and the right of the midpoint. A measure of $\delta$ was created from respondents' answers to questions asking them to indicate, for each coalition, how certain they were that the given coalition would secure a majority of seats after the election. Expectations were measured on 4-point scales. For leftist and centrist voters, the rating of the left coalition was subtracted from the rating of the right coalition, and vice versa for rightist voters.

\section{I. Findings}

Table 2 shows the estimation results. Many coefficients come out insignificant; nevertheless, those that reach statistical significance show the predicted effects. In particular, the predictions seem to bear out for rightist voters and for the group of noncentrist voters as a whole in Austria. The results for rightist voters in Germany also point in the expected direction, although they do not reach statistical significance. Note that in the interactive models the coefficients on $\delta$ represent the effects of expectations for voters at the extreme ends. What matters is whether the main effect of $\delta$ and the interaction term jointly yield sizable positive effects for higher values of $u_{M}$. Apparently that is the case for rightist voters in both samples: for $u_{M}=1$ and for higher values of $u_{M}$, the net effect of expectations on voting for a centrist party is positive. For leftist voters in the Austrian sample, expectations do not seem to have any effect at all; in the German sample their net effect is negative even for high values of $u_{M}$. Judging from their Wald test statistics, the explanatory power of the models for leftist voters is virtually zero.

The negative coefficients obtained for centrist voters run against hypothesis (d). Although insignificant, they suggest that, if expectations exert any systematic effect, centrist voters expecting the right coalition to lead the left coalition should be more (not less) likely to vote for the center-right party. ${ }^{17}$ Perhaps, centrist voters expected either a left or a right coalition to form with certainty and hence decided to support the more centrist of the coalition members. While this may comport with the idea of strategic balancing (Bargsted and Kedar, 2009), it is at odds with the outcome of the Austrian election, which was, in fact, a centrist coalition. Another possibility is that centrist coalitions in both countries might not be very popular and that most voters who position themselves at the ideological center might still prefer a left or a right coalition. Treating centrists as either leftists or rightists leaves the results for each group substantively unchanged in the Austrian sample, which lends some support to the argument. In the German sample, however, it makes the positive result for rightist voters largely disappear. Thus far, the findings provide some tentative results but the evident lack of control over central predictor variables really calls for experimental tests of the theory in the future.

\section{Conclusion}

A long-standing view among scholars of elections is that voters in PR elections simply vote their preference. By contrast, the foregoing analysis suggests that, when prospective government coalitions are identifiable ex ante, voters who inform their decision through 
Table 2. Testing the predictions: centrist and noncentrist voters' choices (Austrian Election Study 2008; German Longitudinal Election Study 2009).

\begin{tabular}{|c|c|c|c|c|c|c|c|c|}
\hline \multicolumn{2}{|l|}{ Country } & \multicolumn{2}{|c|}{ Leftist voters } & \multicolumn{2}{|c|}{ Rightist voters } & \multicolumn{2}{|c|}{ Noncentrists } & \multirow{3}{*}{$\begin{array}{r}\text { Centrists } \\
\begin{array}{c}-0.201 \\
(0.159)\end{array}\end{array}$} \\
\hline \multirow[t]{10}{*}{ Austria } & $\delta$ & -0.013 & -0.095 & $0.356^{\mathrm{a}}$ & 0.012 & $0.165^{a}$ & -0.066 & \\
\hline & & $(0.097)$ & $(0.165)$ & $(0.159)$ & $(0.253)$ & $(0.078)$ & $(0.136)$ & \\
\hline & $u_{M}$ & & -0.044 & & $0.303^{a}$ & & 0.096 & \\
\hline & & & $(0.085)$ & & $(0.145)$ & & $(0.069)$ & \\
\hline & $\delta \times u_{M}$ & & 0.038 & & 0.155 & & $0.110^{\mathrm{a}}$ & \\
\hline & & & $(0.066)$ & & $(0.102)$ & & $(0.053)$ & \\
\hline & Const. & $0.315^{a}$ & $0.418^{b}$ & $1.472^{\mathrm{a}}$ & $0.761^{\mathrm{a}}$ & $0.693^{\mathrm{a}}$ & $0.485^{a}$ & $-0.363^{b}$ \\
\hline & & $(0.121)$ & $(0.216)$ & $(0.203)$ & $(0.366)$ & $(0.098)$ & $(0.183)$ & $(0.193)$ \\
\hline & Wald $\chi^{2}$ & 0.017 & 1.223 & $5.045^{a}$ & $9.108^{a}$ & $4.420^{\mathrm{a}}$ & $8.981^{a}$ & 1.611 \\
\hline & $N$ & 423 & 423 & 193 & 193 & 616 & 616 & 162 \\
\hline \multirow[t]{10}{*}{ Germany } & $\delta$ & -0.171 & $-0.07 \mid$ & $0.363^{b}$ & -0.113 & -0.127 & -0.239 & -0.235 \\
\hline & & $(0.195)$ & $(0.550)$ & $(0.216)$ & $(0.495)$ & $(0.104)$ & $(0.268)$ & $(0.364)$ \\
\hline & $u_{M}$ & & 0.115 & & 0.314 & & 0.086 & \\
\hline & & & $(0.218)$ & & $(0.308)$ & & $(0.127)$ & \\
\hline & $\delta \times u_{M}$ & & -0.036 & & 0.194 & & 0.042 & \\
\hline & & & $(0.189)$ & & $(0.170)$ & & $(0.091)$ & \\
\hline & Const. & 0.268 & -0.051 & $1.307^{a}$ & 0.508 & $0.433^{\mathrm{a}}$ & 0.197 & 0.043 \\
\hline & & $(0.274)$ & $(0.655)$ & $(0.353)$ & $(0.886)$ & $(0.147)$ & $(0.38 I)$ & $(0.377)$ \\
\hline & Wald $\chi^{2}$ & 0.764 & 1.046 & $2.839^{b}$ & 4.951 & 1.497 & 1.951 & 0.417 \\
\hline & $N$ & 135 & 135 & $|4|$ & $|4|$ & 276 & 276 & 53 \\
\hline
\end{tabular}

$\delta$ : Difference in expected seats of $R$ and $L$ (for leftist and centrist voters), resp. $L$ and $R$ (for rightist voters). $u_{M}$ : Voter closeness to center point on left-right scale: 0 'farthest' 4 'closest'.

Entries are logit coefficients (standard errors in parentheses).

${ }^{\mathrm{a}} p<.05$ two-tailed.

${ }^{\mathrm{b}} p<.1$ two-tailed.

public opinion polls face incentives to use their vote in order to influence which coalition wins, instead of simply expressing their preference by voting for the party they like best. For a theoretically interested audience the analysis offered a new way of looking at strategic voting under PR, one that provides insights into incentives that have hitherto gone largely unexamined. For empirical workers it provided testable and intuitive predictions about a seemingly complex phenomenon: strategic voting for coalitions.

Possible avenues for future work include: testing the model's predictions within the setting of a controlled experiment; extending the current framework, for example, by not ruling out, a priori, the possibility of single party majorities, or by allowing for other forms of coalition building (see Section 2.3). From a normative perspective, the model may also help elucidate the welfare consequences of strategic voting under PR. So far, these have been studied solely within the framework of single-winner electoral systems (cf. Lehtinen, 2008).

At the very least, the analysis points to the importance of information circulating prior to an election, particularly the information conveyed by public opinion polls. Observers of elections should come away from this with the warning that inferring the electorates' 
preferences from voting results can be misleading - even under PR - because the same voters may vote differently if they expect a different outcome.

\section{Appendix A. Lemma I}

Lemma A.1. Using the multinomial distribution with parameter vector $\pi$ the probabilities of pivotal situations 1-12 are given by

$$
\begin{aligned}
p_{1} & =\operatorname{Pr}\left(s_{L}=\frac{N}{2}, s_{M}<\frac{N}{2}, s_{R}<\frac{N}{2}, 1 \leq s_{o}<\frac{N}{2}\right) \\
& =\sum_{k=1}^{\frac{N}{2}-1} \sum_{t=1}^{\frac{N}{2}-1} \sum_{m=0}^{X} \frac{N !}{t !\left(\frac{N}{2}-t\right) ! m !\left(\frac{N}{2}-k-m\right) ! k !}\left(\pi_{l}\right)^{t}\left(\pi_{c l}\right)^{\frac{N}{2}-t}\left(\pi_{c r}\right)^{m}\left(\pi_{r}\right)^{\frac{N}{2}-k-m}\left(\pi_{o}\right)^{k}
\end{aligned}
$$

where $X=\min \left(t-1, \frac{N}{2}-k\right)$,

$$
\begin{aligned}
p_{2}= & \operatorname{Pr}\left(s_{L}=\frac{N}{2}, s_{M}>\frac{N}{2}, s_{R}<\frac{N}{2}, 1 \leq s_{o}<\frac{N}{2}\right) \\
= & \sum_{k=1}^{\frac{N}{2}-2} \sum_{t=1}^{\frac{N}{2}-k-1} \sum_{m=t+1}^{\frac{N}{2}-k} \frac{N !}{t !\left(\frac{N}{2}-t\right) ! m !\left(\frac{N}{2}-k-m\right) ! k !}\left(\pi_{l}\right)^{t}\left(\pi_{c l}\right)^{\frac{N}{2}-t}\left(\pi_{c r}\right)^{m}\left(\pi_{r}\right)^{\frac{N}{2}-k-m}\left(\pi_{o}\right)^{k} \\
p_{3} & =\operatorname{Pr}\left(s_{L}<\frac{N}{2}, s_{M}<\frac{N}{2}, s_{R}=\frac{N}{2}, 1 \leq s_{o}<\frac{N}{2}\right) \\
& =\sum_{k=1}^{\frac{N}{2}-1} \sum_{t=1}^{\frac{N}{2}-1} \sum_{m=0}^{X} \frac{N !}{\left(\frac{N}{2}-k-m\right) ! m !\left(\frac{N}{2}-t\right) ! t ! k !}\left(\pi_{l}\right)^{\frac{N}{2}-k-m}\left(\pi_{c l}\right)^{m}\left(\pi_{c r}\right)^{\frac{N}{2}-t}\left(\pi_{r}\right)^{t}\left(\pi_{o}\right)^{k}
\end{aligned}
$$

where $X=\min \left(t-1, \frac{N}{2}-k\right)$,

$$
\begin{aligned}
p_{4} & =\operatorname{Pr}\left(s_{L}<\frac{N}{2}, s_{M}>\frac{N}{2}, s_{R}=\frac{N}{2}, 1 \leq s_{o}<\frac{N}{2}\right) \\
= & \sum_{k=1}^{\frac{N}{2}-2} \sum_{t=1}^{\frac{N}{2}-k-1} \sum_{m=t+1}^{\frac{N}{2}-k} \frac{N !}{\left(\frac{N}{2}-k-m\right) ! m !\left(\frac{N}{2}-t\right) ! t ! k !}\left(\pi_{l}\right)^{\frac{N}{2}-k-m}\left(\pi_{c l}\right)^{m}\left(\pi_{c r}\right)^{\frac{N}{2}-t}\left(\pi_{r}\right)^{t}\left(\pi_{o}\right)^{k} \\
p_{5} & =\operatorname{Pr}\left(s_{L}<\frac{N}{2}, s_{M}=\frac{N}{2}, s_{R}<\frac{N}{2}, 2 \leq s_{o}<\frac{N}{2}\right) \\
& =\sum_{k=2}^{\frac{N}{2}-1} \sum_{t=1}^{\frac{N}{2}-1} \sum_{m=x}^{X} \frac{N !}{m ! t !\left(\frac{N}{2}-t\right) !\left(\frac{N}{2}-k-m\right) ! k !}\left(\pi_{l}\right)^{m}\left(\pi_{c l}\right)^{t}\left(\pi_{c r}\right)^{\frac{N}{2}-t}\left(\pi_{r}\right)^{\frac{N}{2}-k-m}\left(\pi_{o}\right)^{k}
\end{aligned}
$$


where $x=\max \left(0, \frac{N}{2}-k-t+1\right)$ and $X=\min \left(\frac{N}{2}-k, \frac{N}{2}-t-1\right)$,

$$
\begin{aligned}
p_{6} & =\operatorname{Pr}\left(s_{L}<\frac{N}{2}, s_{M}=\frac{N}{2}, s_{R}>\frac{N}{2}, 0 \leq s_{o}<\frac{N}{2}\right) \\
& =\sum_{k=0}^{\frac{N}{2}-2} \sum_{t=1}^{Y} \sum_{m=t+1}^{X} \frac{N !}{\left(\frac{N}{2}-k-m\right) ! t !\left(\frac{N}{2}-t\right) m ! k !}\left(\pi_{l}\right)^{\frac{N}{2}-k-m}\left(\pi_{c l}\right)^{t}\left(\pi_{c r}\right)^{\frac{N}{2}-t}\left(\pi_{r}\right)^{m}\left(\pi_{o}\right)^{k}
\end{aligned}
$$

where $X=\min \left(\frac{N}{2}-k, \frac{N}{2}-1\right)$ and $Y=\min \left(\frac{N}{2}-k-1, \frac{N}{2}-2\right)$,

$$
\begin{aligned}
p_{7} & =\operatorname{Pr}\left(s_{L}<\frac{N}{2}, s_{M}=s_{R}=\frac{N}{2}, 1 \leq s_{o}<\frac{N}{2}\right) \\
& =\sum_{k=1}^{\frac{N}{2}-1} \sum_{t=1}^{X} \frac{N !}{\left(\frac{N}{2}-k-t\right) ! t !\left(\frac{N}{2}-t\right) ! t ! k !}\left(\pi_{l}\right)^{\frac{N}{2}-k-t}\left(\pi_{c l}\right)^{t}\left(\pi_{c r}\right)^{\frac{N}{2}-t}\left(\pi_{r}\right)^{t}\left(\pi_{o}\right)^{k}
\end{aligned}
$$

where $X=\min \left(\frac{N}{2}-k, \frac{N}{2}-1\right)$,

$$
\begin{aligned}
p_{8} & =\operatorname{Pr}\left(s_{L}>\frac{N}{2}, s_{M}=\frac{N}{2}, s_{R}<\frac{N}{2}, 0 \leq s_{o}<\frac{N}{2}\right) \\
& =\sum_{k=0}^{\frac{N}{2}-2} \sum_{t=1}^{Y} \sum_{m=t+1}^{X} \frac{N !}{m !\left(\frac{N}{2}-t\right) ! t !\left(\frac{N}{2}-k-m\right) ! k !}\left(\pi_{l}\right)^{m}\left(\pi_{c l}\right)^{\frac{N}{2}-t}\left(\pi_{c r}\right)^{t}\left(\pi_{r}\right)^{\frac{N}{2}-k-m}\left(\pi_{o}\right)^{k}
\end{aligned}
$$

where $X=\min \left(\frac{N}{2}-k, \frac{N}{2}-1\right)$ and $Y=\min \left(\frac{N}{2}-k-1, \frac{N}{2}-2\right)$,

$$
\begin{aligned}
p_{9} & =\operatorname{Pr}\left(s_{L}=s_{M}=\frac{N}{2}, s_{R}<\frac{N}{2}, 1 \leq s_{o}<\frac{N}{2}\right) \\
& =\sum_{k=1}^{\frac{N}{2}-1} \sum_{t=1}^{X} \frac{N !}{t !\left(\frac{N}{2}-t\right) ! t !\left(\frac{N}{2}-k-t\right) ! k !}\left(\pi_{l}\right)^{t}\left(\pi_{c l}\right)^{\frac{N}{2}-t}\left(\pi_{c r}\right)^{t}\left(\pi_{r}\right)^{\frac{N}{2}-k-t}\left(\pi_{o}\right)^{k}
\end{aligned}
$$

where $X=\min \left(\frac{N}{2}-k, \frac{N}{2}-1\right)$,

$$
\begin{aligned}
p_{10}= & \operatorname{Pr}\left(s_{L}=s_{R}=\frac{N}{2}, s_{M}<\frac{N}{2}, s_{o}=0\right) \\
= & \sum_{k=2}^{\frac{N}{2}-1} \sum_{t=1}^{k-1} \frac{N !}{k !\left(\frac{N}{2}-k\right) ! t !\left(\frac{N}{2}-t\right) !}\left(\pi_{l}\right)^{k}\left(\pi_{c l}\right)^{\frac{N}{2}-k}\left(\pi_{c r}\right)^{t}\left(\pi_{r}\right)^{\frac{N}{2}-t} \\
p_{11}= & \operatorname{Pr}\left(s_{L}=s_{R}=\frac{N}{2}, s_{M}>\frac{N}{2}, s_{o}=0\right) \\
= & \sum_{k=1}^{\frac{N}{2}-2} \sum_{t=k+1}^{\frac{N}{2}-1} \frac{N !}{k !\left(\frac{N}{2}-k\right) ! t !\left(\frac{N}{2}-t\right) !}\left(\pi_{l}\right)^{k}\left(\pi_{c l}\right)^{\frac{N}{2}-k}\left(\pi_{c r}\right)^{t}\left(\pi_{r}\right)^{\frac{N}{2}-t}
\end{aligned}
$$




$$
\begin{aligned}
p_{12} & =\operatorname{Pr}\left(s_{L}=s_{M}=s_{R}=\frac{N}{2}, s_{o}=0\right) \\
& =\sum_{k=1}^{\frac{N}{2}-1} \frac{N !}{k !\left(\frac{N}{2}-k\right) ! k !\left(\frac{N}{2}-k\right) !}\left(\pi_{k}\right)^{k}\left(\pi_{c l}\right)^{\frac{N}{2}-k}\left(\pi_{c r}\right)^{k}\left(\pi_{r}\right)^{\frac{N}{2}-k} .
\end{aligned}
$$

Proof. All pivot probabilities are subject to the constraint that $s_{l}, s_{c l}, s_{c r}$ and $s_{r}$ each be at most $\frac{N}{2}-1$ to ensure that a voter is only pivotal in bringing about coalition majorities, not single party majorities. For ease of exposition, begin with the equation for $p_{6}$. To derive this equation, note that from the requirements $s_{c l}+s_{c r}=\frac{N}{2}$ and $s_{c r}+s_{r}>\frac{N}{2}$ it follows that $s_{r} \geq s_{c l}+1$. From this and $s_{c l}+s_{c r}=\frac{N}{2}$, it follows that $s_{l} \leq \frac{N}{2}-s_{c l}+1$ and therefore $s_{L}<\frac{N}{2}$, as required. Together, these conditions are imposed through the exponents on $\pi_{l}, \pi_{c l}, \pi_{c r}$ and $\pi_{r}$ and through the lower limit of the summation index $m$. Concerning the other summation limits, note first that the above conditions hold even if $o$ wins no seats; thus the lower limit of $s_{o}$ is $k=0$. The lower limit of $s_{c l}$ is $t=1$, since one of the parties in $M$ must win at least one seat to ensure the absence of a single party majority. For similar reasons, the upper limit of $m$ cannot exceed $\frac{N}{2}-1$. For $k>1$ the upper limit on $m$ must be $\frac{N}{2}-k$ due to $s_{M}=\frac{N}{2}$. From the lower limits $t=1$ and $m=t+1$ it follows that $m \geq 2$, which implies $\frac{N}{2}-2$ as the upper limit of $k$. From $t \leq m-1$ and the fact that $m$ is at most $\frac{N}{2}-k$ if $k>0$, it follows that $\frac{N}{2}-k-1$ is an upper limit of $t$ if $k>0$. For $k=0$ the upper limit on $t$ is bounded by $\frac{N}{2}-2$ to ensure that $m \leq \frac{N}{2}-1$, which completes the formula for $p_{6}$. Formulas for $p_{1}$ through $p_{4}$ and $p_{7}$ through $p_{12}$ can be derived in an analogous fashion.

Delineating the outcome space for situation 5 requires additional considerations. First, note that the lower limit on $k$ in the formula for $p_{1}$ must be $k=2$, since, for $s_{o}<2$, it follows that $s_{L}+s_{R} \geq N-1$ in which case $s_{L}<\frac{N}{2}$ and $s_{R}<\frac{N}{2}$ cannot simultanously hold. Exclusion of a single party majority imposes on $k$ the upper limit $\frac{N}{2}-1$. The latter restriction also imposes the upper and lower limits on $t$. To see that no other restriction applies to $t$, note that even in the extreme case of $k=2$ (i.e. $\frac{N}{2}-2$ seats need to be allocated among $l$ and $r$ ) and with $t=\frac{N}{2}-1, s_{L}<\frac{N}{2}$ and $s_{R}<\frac{N}{2}$ can still be satisfied by setting $s_{l}=0$ and $s_{r}=\frac{N}{2}-2$. Increasing $k$ can only decrease $s_{L}$ and $s_{R}$ given that $s_{M}=\frac{N}{2}$. Thus, if conditions $s_{L}<\frac{N}{2}$ and $s_{R}<\frac{N}{2}$ can be satisfied for $k=2$ and $t=\frac{N}{2}-1$, they can also be satisfied for $k>2$ and $t=\frac{N}{2}-1$, which establishes $\frac{N}{2}-1$ and $t=1$ as upper and lower limits on $t$. The first upper limit on $m, \frac{N}{2}-k$, follows from the fact that no more seats can be allocated to either $l$ or $r$, given $k \geq 2$ and $s_{M}=\frac{N}{2}$. The second upper limit, $\frac{N}{2}-t-1$, ensures that $s_{L}<\frac{N}{2}$ and $s_{R}<\frac{N}{2}$, which, due to $s_{c r}=\frac{N}{2}-s_{c l}$, holds only if $s_{l} \leq s_{c r}-1$ and $s_{r} \leq s_{c l}-1$. The lower limit on $m$ follows from noticing that the number of possible allocations of seats among $l$ and $r$ is jointly determined by $t$ and $k$ : first, it is determined by $t$ such that if $t=1$ there is only one possible allocation of seats among $r$ and $l$ in which $s_{r}=0$ and all remaining $\frac{N}{2}-k$ seats go to $l$. Increasing $t$ by one (i.e. distributing seats more equally among parties in $M$ ), ceteris paribus, frees up one seat for allocation to either $l$ or $r$, thus increasing the number of admissible outcomes by one. The expression $\frac{N}{2}-k-t+1$ guarantees that the lower limit and upper limit coincide if $t=1$ and that the lower limit decreases irrespective of $k$ as $t$ increases. Second, the lower limit is determined by $k$ such that if $k=2$ there is only one possible allocation 
of seats among $l$ and $r$ in which $s_{l}=\frac{N}{2}-t-1$ and $s_{r}=t-1$. Increasing $k$ by one (i.e. reducing the number of seats available for allocation among $l$ and $r$ ), ceteris paribus, frees up one seat for allocation to either $l$ or $r$, thus increasing the number of admissible outcomes by one. The expression $\frac{N}{2}-k-t+1$ guarantees that the lower limit and upper limit coincide if $k=2$ and that the lower limit decreases irrespective of $t$ as $k$ increases. Finally, to ensure $m \geq 0$ the lower limit is bound by zero.

\section{Appendix B. Omitted proofs}

Proof of Proposition 2.1. From Table 1, a leftist voter with $u_{M}>\left(u_{L}+u_{R}\right) / 2$ optimally chooses party $c l$ over party $l$ if and only if

$$
\begin{array}{r}
\left(p_{5}+p_{7}\right)\left(\frac{u_{M}}{2}-\frac{u_{L}+u_{R}}{4}\right)+p_{6}\left(\frac{u_{M}+u_{R}}{2}-u_{R}\right)> \\
\left(p_{8}+p_{9}+p_{12}\right)\left(u_{L}-\frac{u_{L}+u_{M}}{2}\right)
\end{array}
$$

Setting $u_{L}=1$ and $u_{R}=0$, the criterion becomes

$$
\begin{gathered}
\left(p_{5}+p_{7}\right)\left(\frac{u_{M}}{2}-\frac{1}{4}\right)+p_{6} \frac{u_{M}}{2}>\left(p_{8}+p_{9}+p_{12}\right)\left(1-\frac{1+u_{M}}{2}\right) \\
\left(\left(p_{5}+p_{7}\right)\left(1-\frac{1}{2 u_{M}}\right)+p_{6}\right) \frac{u_{M}}{2}>\left(p_{8}+p_{9}+p_{12}\right)\left(1-\frac{1+u_{M}}{2}\right) \\
\frac{\left(p_{5}+p_{7}\right)\left(1-\frac{1}{2 u_{M}}\right)+p_{6}}{p_{8}+p_{9}+p_{12}}>\frac{1-u_{M}}{u_{M}}
\end{gathered}
$$

as required.

A leftist voter with $u_{M}<\left(u_{L}+u_{R}\right) / 2$ chooses party $c l$ over party $l$ if and only if

$$
\begin{array}{r}
p_{6}\left(\frac{u_{M}+u_{R}}{2}-u_{R}\right)> \\
\left(p_{5}+p_{7}\right)\left(\frac{u_{L}+u_{R}}{4}-\frac{u_{M}}{2}\right)+\left(p_{8}+p_{9}+p_{12}\right)\left(u_{L}-\frac{u_{L}+u_{M}}{2}\right)
\end{array}
$$

After normalizing voter utility, the criterion becomes

$$
\begin{aligned}
\left(p_{5}+p_{7}\right)\left(\frac{1}{4}-\frac{u_{M}}{2}\right)+\left(p_{8}+p_{9}+p_{12}\right)\left(1-\frac{1+u_{M}}{2}\right) & <p_{6} \frac{u_{M}}{2} \\
\left(\left(p_{5}+p_{7}\right) \frac{\frac{1}{4}-\frac{u_{M}}{2}}{1-\frac{1+u_{M}}{2}}+\left(p_{8}+p_{9}+p_{12}\right)\right)\left(1-\frac{1+u_{M}}{2}\right) & <p_{6} \frac{u_{M}}{2} \\
\left(\left(p_{5}+p_{7}\right) \frac{1-2 u_{M}}{2-2 u_{M}}+\left(p_{8}+p_{9}+p_{12}\right)\right)\left(1-\frac{1+u_{M}}{2}\right) & <p_{6} \frac{u_{M}}{2} \\
\frac{p_{6}}{\left(p_{5}+p_{7}\right) \frac{1-2 u_{M}}{2-2 u_{M}}+p_{8}+p_{9}+p_{12}} & >\log \frac{1-u_{M}}{u_{M}}
\end{aligned}
$$

as required. 
The optimal voting criterion for a leftist voter with $u_{M}=\left(u_{L}+u_{R}\right) / 2$ follows readily from normalizing utility and substituting $u_{M}=\frac{1}{2}$ into the expression for $\eta$.

Proof of Proposition 2.2. A centrist voter chooses party $\mathrm{cl}$ over party $\mathrm{cr}$ if and only if

$$
\begin{array}{r}
p_{3}\left(\frac{u_{M}+u_{R}}{2}-u_{R}\right)+p_{4}\left(u_{M}-\frac{u_{M}+u_{R}}{2}\right)+p_{7}\left(u_{M}-\frac{u_{M}+u_{R}}{2}\right)> \\
p_{1}\left(\frac{u_{M}+u_{L}}{2}-u_{L}\right)+\left(p_{2}+p_{9}\right)\left(u_{M}-\frac{u_{M}+u_{L}}{2}\right)
\end{array}
$$

Setting $u_{M}=1$ and $u_{L}=u_{R}=0$, all payoffs become $\frac{1}{2}$ and part (a) of Proposition 2.2 follows from simple rearranging.

To obtain part (b) compare abstention to a vote for either $c l$ or $c r$ : from Table 1 note that abstention yields a positive payoff over voting for either $\mathrm{cl}$ or $\mathrm{cr}$ in situations 10 and 11 , a negative payoff in situations 5-9, and a zero payoff in situations $1-4$ and 12 . Setting $u_{M}=1$ and $u_{L}=u_{R}=0$ it is easy to see that, in each situation, the payoff of abstention over a centrist vote amounts to $\frac{1}{2}$. Rearranging the decision criterion leads to part (b).

\section{Appendix C. Predictions for a four-party system}

To show that the predictions established in Section 2.1 do not depend on the presence of noncoalition parties, we shall repeat the above analysis, setting $\pi_{o}=s_{o}=0$.

Proposition C.1. Excluding $o, \eta=\frac{p_{6}}{p_{8}+p_{12}}$ and $\iota=\frac{p_{10}+p_{11}}{p_{6}+p_{8}}$, where $p_{6}=\operatorname{Pr}\left(s_{L}<\frac{N}{2}, s_{M}=\frac{N}{2}, s_{R}>\frac{N}{2}, s_{o}=0\right), p_{8}=\operatorname{Pr}\left(s_{L}>\frac{N}{2}, s_{M}=\frac{N}{2}, s_{R}<\frac{N}{2}, s_{o}=0\right)$, and $p_{10}, p_{11}$ and $p_{12}$ are stated in Lemma A.1. Furthermore, a centrist voter is indifferent between choosing $\mathrm{cl}$ or $\mathrm{cr}$.

Proof. According to Lemma A.1, $s_{o}=0$ implies $p_{1}=p_{2}=p_{3}=p_{4}=p_{5}=p_{7}=p_{9}=$ 0 . Thus, pivotal situations 1 through 5 , as well as 7 and 9 (see Table 1) drop out of the voter's decision criterion. The probabilities $p_{6}$ and $p_{8}$ are readily obtained from Lemma A. 1 applying the constraint $k=0$. Since situations 7 and 9 cannot occur when $o$ is excluded, the reason for a centrist voter to distinguish between $\mathrm{cl}$ and $\mathrm{cr}$ disappears.

Note that, in the four-party case, a centrist voter either abstains or votes for a centrist party, but it does not matter which one she chooses. Figure 3 shows that, on average, $\eta$ increases in $\delta$ but not in $\pi_{M}$. Furthermore $\iota$ decreases in $|\delta|$ and increases in $\left|\pi_{M}-0.5\right|$, on average.

\section{Appendix D. Data and measures}

The Austrian election survey was conducted by telephone on a representative sample of 1951 Austrian voters. Sampling weights are used to correct for design-based oversampling of voters from the state of Carinthia. The German data come from a pre-election survey administered to an online access panel of 985 voters about four weeks prior to the election. Survey weights are used to adjust the online sample to German census data (Mikrozensus). Both datasets are available at the GESIS Data Archive, study numbers ZA4888 and ZA5337. 

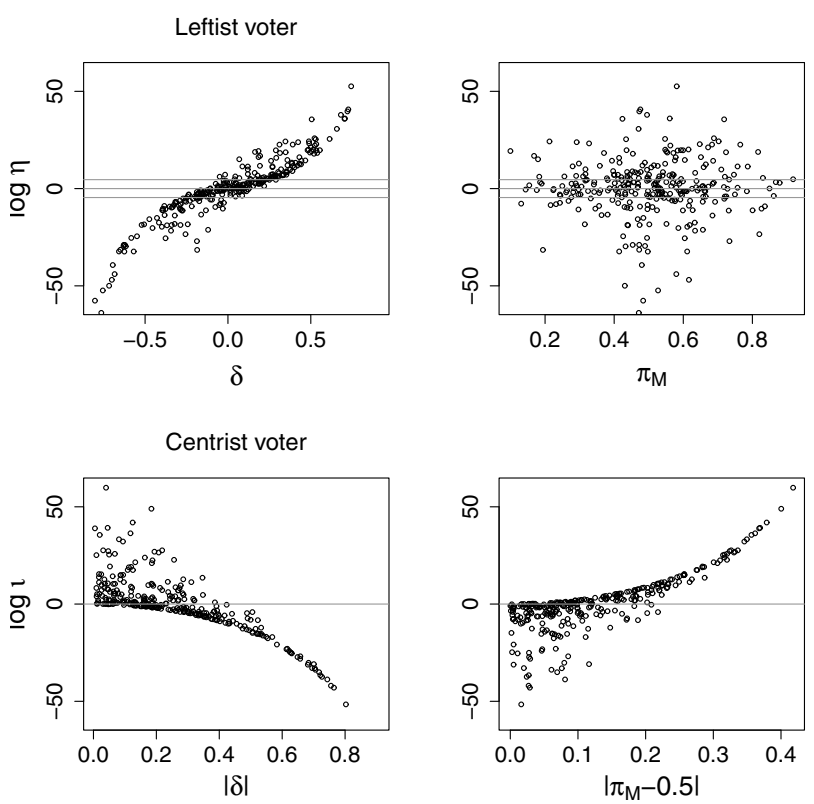

Figure 3. The strategic incentive of leftist and centrist voters depending on $\delta$ and $\pi_{M}$. Here, noncoalition parties are excluded, i.e. their probability of winning seats is set to zero. For ease of display, each incentive variable and its associated threshold value have been log transformed. In the two upper panels reference lines indicate log transformed threshold levels, $\tau$, of a leftist voter with $u_{M}=0.01, u_{M}=0.5$ and $u_{M}=0.99$. In the lower two panels the voter's log transformed abstention threshold is indicated by a reference line at zero. Predictions based on 300 simulation runs.

The question used to measure coalition expectations in both surveys reads: 'Für wie wahrscheinlich halten Sie es, dass die folgenden Parteien zusammen rein rechnerisch eine Mehrheit zur Regierungsbildung im neuen [Nationalrat/Bundestag] haben werden? Sehr unwahrscheinlich, eher unwahrscheinlich, eher wahrscheinlich, sehr wahrscheinlich'

This might be translated as: "What do you think, how likely is it that the following parties together will secure enough seats to form a majority government in the next [Nationalrat/Bundestag]?'

Respondents were then presented with a list of coalitions and had to rate each one on a four point scale with categories labeled 'very unlikely', 'rather unlikely', 'rather likely' and 'very likely'.

\section{Acknowledgements}

I thank Michael Bechtel, Thomas Bräuninger, Joachim Behnke, Christophe Crombez, Wim van Gestel, Thomas Gschwend, Indridi H Indridason, Sebastian Köhler, Aki Lehtinen, Eric Linhart, Lionel Marquis, Franz Urban Pappi, Sigrid Rossteutscher, Gerald Schneider and Susumu Shikano for comments. Previous versions of this paper have been presented at the General Conferences 
of the European Consortium for Political Research 2009 and 2011, the Annual Meeting of the 'Arbeitskreis Wahlen und Politische Einstellungen 2010' and the Annual Meeting of the European Public Choice Society 2010.

\section{Funding}

The author(s) received no financial support for the research and/or authorship of this article.

\section{Notes}

1. Empirically, it is not always the case that government coalitions command a majority of seats. Denmark, for example, looks upon a long history of minority governments. While incentives for strategic voting might also exist under minority governments (see the discussion in Section 2.3), the present study confines itself to the case of majority coalitions.

2. Several related studies identify incentives for strategic voting under PR without assuming coalition building. Ortuño-Ortín (1997) and De Sinopoli and Iannantuoni (2007) assume unanimous (seat-weighted) decision-making by all parties in parliament (for a critique of this approach, see Indridason, 2011). Slinko and White (2010) show that strategic incentives always exist if voters decide with an eye on parties' post-election voting power in parliament (this may be seen as a variant of the coalition-oriented strategic voting considered here, in cases where voters are unable to identify the set of coalitions likely to form after the election).

3. Each of these criteria features prominently in the cabinet formation literature and theoretical justifications are given, for example, in Riker (1962) and Axelrod (1970); see also Goodin et al. (2007) for similar assumptions in studying coalition agreements and strategic voting.

4. It is sometimes argued that voters in proportional elections may also be 'selection pivotal' (Baron and Diermeier, 2001) or engage in 'strategic sequencing' (Cox, 1997). Both arguments suggest that voters may want to influence which party gets the first try at forming a coalition (see also Indridason, 2011). For such strategic behavior to be feasible, however, voters must be able to predict a priori the outcome of the negotiations. This is not necessary in the setting studied here.

5. Intuitively, this can be justified by realizing that, in these indeterminate cases, one of the two possible coalitions will ultimately form and, while it is beyond the voter to decide which one, the mere possiblity of an alternative government should make an indeterminate outcome either preferrable to certain unique outcomes or not, depending on the voter's preference.

6. This payoff statement could also be interpreted in the sense that, instead of forming a threeparty coalition, the two centrist parties would form a minority government, which would receive support by $l$ and $r$ with equal probability.

7. Instead of treating centrists as indifferent between $L$ and $R$, one could assume that some centrists prefer $L$ over $R$, or vice versa. The current analysis does not consider these cases. If we assumed that some centrists were not indifferent between $L$ and $R$, then those centrists' payoffs from voting $\mathrm{cl}$ in situations 1, 3 and 10 would depend on their strength of preference for $L$ over $R$ (resp. $R$ over $L$ ). For example, if some centrists strongly preferred $L$ over $R$, their payoff in situation 1 might become positive. Also, in situation 10, a centrist who strongly prefers $L$ over $R$ might prefer to install a government by $L$ rather than accept a lottery over three-party coalitions. This should have only minor implications for centrists' reactions to polls, however (see Section 2.1). In particular, centrists who strongly prefer $L$ over $R$ (resp. $R$ over $L$ ) would vote for $\mathrm{cl}$ (resp. $\mathrm{cr}$ ) but only if they expected $M$ to win less than half the seats (as in situations 1, 3 and 10). Otherwise-if $M$ is expected to win a majority of seats, or if a centrist's preference between $L$ and $R$ is weak - the predictions should be similar to those presented in Section 2.1 . 
8. While we could also derive predictions based on expected seat shares for $R$ and $L$ alonedoing so, one finds an increase (decrease) in the incentive to vote for a centrist party, the higher (lower) the expected seat share of the disliked coalition-focusing on the difference in seat shares means that voters do not have to have in mind numerical estimates of their preferred coalition's likely share of parliamentary seats. They just have to be able to compare the prospects of their preferred coalition with those of the disliked coalition-a fairly straightforward task.

9. In manipulating expected seats for $M$ (resp. o), note that the expected division of seats between $L$ and $R$ was kept at zero.

10. Given the burden involved in analytically deriving the functional derivative of the strategic incentive with respect to $\delta, \pi_{M}$ and $\pi_{o}$, the straightforward Monte Carlo solution appears preferable. The rationale for using the simulation is to neutralize the effects of variables that one would ideally keep constant in a comparative static analysis by letting them vary at random.

11. A situation where $L$ and $R$ polled neck-and-neck is much less interesting. Basically, leftist and rightist voters in this situation would not be swayed by strategic incentives. Centrist voters would, likewise, choose more or less randomly between either of the two centrist parties; or, if $M$ was expected to secure (resp. fail) a parliamentary majority by a large margin, they would abstain. If $M$ was initially expected to be very strong, abstention by strategic centrist voters would drive down its prospects but after the next round of polling it would lead the same voters to reverse their decision and vote for a centrist party again.

12. Abstention would be an option for centrist voters only if the centrist coalition fared very well (resp. bad) in the polls and the imbalance between $L$ and $R$ was not too large. If this happened, the consequences of abstention would be the same as discussed in the previous note.

13. The effects of leftist and rightist voters' strategic switching are less consequential. They only affect $M$ 's standing in the polls and the effects of noncentrist voters' strategic migrations should largely cancel each other out - at least as long as we assume that both groups are not too unequal in terms of their size and with respect to voters' preferences toward $M$. Even if not, noncentrists would affect centrists' behaviors only if $M$ 's electoral prospects were increased (resp. decreased) to a level where centrist voters would be better off abstaining. If so, this would restore some of the original imbalance between $L$ and $R$ and bring us back into a situation similar to the initial one.

14. Note that, in the last situation, voting for $l$ would result in no majority for both coalitions. A leftist voter would prefer such an outcome over a majority for the right three-way coalition if we assume that all four parties will then join a grand coalition.

15. Note that the two conditions in hypothesis (e) together imply that $\pi_{o}$ is small.

16. For coalition signals of Austrian parties, see Debus (2007) and Luther (2008).

17. Note that the negative coefficients do not disappear if the coding of centrists also includes voters at positions 5 and 7 .

\section{References}

Abramson PR, Aldrich JH, Blais A, et al. (2010) Comparing strategic voting under FPTP and PR. Comparative Political Studies 43: 61-90.

Armstrong DA II and Duch RM (2010) Why can voters anticipate post-election coalition formation likelihoods? Electoral Studies 29: 308-315.

Austen-Smith D and Banks J (1988) Elections, coalitions and legislative outcomes. American Political Science Review 82(2): 405-422. 
Axelrod R (1970) Conflict of Interest: A Theory of Divergent Goals with Applications to Politics. Chicago, IL: Markham.

Bargsted M and Kedar O (2009) Coalition-targeted Duvergerian voting: how expectations affect voter choice under proportional representation. American Journal of Political Science 53(2): 307-323.

Baron DP and Diermeier D (2001) Elections, governments and parliaments in proportional representation systems. Quarterly Journal of Economics 116(3): 933-967.

Blais A, Aldrich JH, Indridason IH et al. (2006) Do voters vote for government coalitions? Testing Downs' pessimistic conclusion. Party Politics 12: 691-705.

Bowler S, Karp J and Donovan T (2010) Strategic coalition voting: evidence from New Zealand. Electoral Studies 29: 350-57.

Cox G (1984) Strategic electoral choice in multimember districts: approval voting in practice? American Journal of Political Science 28: 722-738.

Cox G and Shugart MS (1996) Strategic voting under proportional representation. Journal of Law, Economics and Organization 12: 299-324.

Cox GW (1997) Making Votes Count: Strategic Coordination in the World's Electoral Systems. Cambridge: Cambridge University Press.

Debus M (2007) Pre-electoral Alliances, Coalition Rejections, and Multiparty Governments. Baden-Baden, Germany: Nomos.

Debus M (2009) Pre-electoral commitments and government formation. Public Choice 138: 45-64.

De Sinopoli F and Iannantuoni G (2007) A spatial voting model where proportional rule leads to two-party equilibria. International Journal of Game Theory 35: 267-287.

De Swaan A (1973) Coalition Theories and Cabinet Formations: A Study of Formal Theories of Coalition Formation Applied to Nine European Parliaments after 1918. Amsterdam: Elsevier.

Downs A (1957) An Economic Theory of Democracy. New York: Harper and Row.

Duch RM, May J and Armstrong II DA (2010) Coalition-directed voting in multiparty democracies. American Political Science Review 104: 698-719.

Fey M (1997) Stability and coordination in Duverger's law: a formal model of preelection polls and strategic voting. American Political Science Review 91: 135-147.

Fisher SD (2004) Definition and measurement of tactical voting: the role of rational choice. British Journal of Political Science 34: 125-166.

Forsythe R, Myerson RB, Rietz TA et al. (1993) An experiment on coordination in multi-candidate elections: the importance of polls and election histories. Social Choice and Welfare 10: 223-247.

Forsythe R, Rietz TA, Myerson RB et al. (1996) An experimental study of voting rules and polls in three-candidate elections. International Journal of Game Theory 25: 355-383.

Golder SN (2006) The Logic of Pre-Electoral Coalition Formation. Columbus, OH: Ohio State University Press.

Goodin R, Güth W and Sausgruber R (2007) When to coalesce: early versus late coalition announcement in an experimental democracy. British Journal of Political Science 38: 181-191.

Herrmann M and Pappi FU (2008) Strategic voting in German constituencies. Electoral Studies 27: $228-244$.

Hoffman DT (1982) A model for strategic voting. SIAM Journal on Applied Mathematics 42(4): $751-761$.

Indridason IH (2011) Proportional representation, majoritarian legislatures, and coalitional voting. American Journal of Political Science 55: 955-971.

Laver M and Budge I (eds) (1992) Party Policy and Government Coalitions. Basingstoke, UK: Macmillan.

Laver M and Schofield N (1998) Multiparty Government: The Politics of Coalition in Europe. Ann Arbor, MI: University of Michigan Press.

Lehtinen A (2008) The welfare consequences of strategic voting under approval and plurality voting. European Journal of Political Economy 24: 688-704. 
Linhart E (2007) Rationales Wählen als Reaktion auf Koalitionssignale am Beispiel der Bundestagswahl 2005. Politische Vierteljahresschrift 48: 461-484.

Luther KR (2008) The 2006 Austrian parliamentary election: from bipolarism to forced marriage. West European Politics 31: 1004-1015.

Martin LW and Stevenson RT (2001) Government formation in parliamentary democracy. American Journal of Political Science 45(1): 33-50.

Meffert MF and Gschwend T (2010) Strategic coalition voting: evidence from Austria. Electoral Studies 29: 339-349.

Müller WC and Strøm K (eds.) (1999) Policy, Office, or Votes? How Political Parties in Western Europe Make Hard Decisions. Cambridge: Cambridge University Press.

Müller WC and Strøm K (eds.) (2003) Coalition Governments in Western Europe. Oxford: Oxford University Press.

Myatt DP (2007) On the theory of strategic voting. Review of Economic Studies 74(1): 255-281.

Myerson RB and Weber RJ (1993) A theory of voting equilibria. American Political Science Review 87: $102-114$.

Niou EMS (2001) Strategic voting under plurality and runoff rules. Journal of Theoretical Politics 13: 209-227.

Ortuño-Ortín I (1997) A spatial model of political competition and proportional representation. Social Choice and Welfare 14: 427-438.

Palfrey TR (1989) A mathematical proof of Duverger's law. In: Ordeshook PC (ed) Models of Strategic Choice in Politics. Ann Arbor, MI: University of Michigan Press, pp. 69-91.

Pappi FU (2007) Partei- und Koalitionskriterien der österreichischen Wählerschaft für die Nationalratswahl 2006. Österreichische Zeitschrift für Politikwissenschaft 36: 445-469.

Powell B (2000) Elections as Instruments of Democracy: Majoritarian and Proportional Visions. New Haven, CT: Yale University Press.

Reed SR (1996) Seats and votes: testing Taagepera in Japan. Electoral Studies 15: 71-81.

Rietz TA, Myerson RB and Weber RJ (1998) Campaign finance levels as coordinating signals in three-way experimental elections. Economics and Politics 10: 185-217.

Riker WH (1962) The Theory of Political Coalitions. New Haven, CT: Yale University Press.

Shikano S, Herrmann M and Thurner PW (2009) Strategic voting under proportional representation: threshold insurance in German elections. West European Politics 32: 630-652.

Slinko A and White S (2010) Proportional representation and strategic voters. Journal of Theoretical Politics 22: 301-332.

Strøm K (1990) Minority Government and Majority Rule. Cambridge: Cambridge University Press.

Taagepera R and Shugart MS (1993) Predicting the number of parties: a quantitative model of Duverger's mechanical effect. American Political Science Review 87: 455-464.

Van Holsteyn JJM and Irwin GA (2003) They say it can't be done: strategic voting in multi-party proportional systems. Paper presented at the annual meeting of the American Political Science Association, Philadelphia, PA, 27 August 2003.

Warwick P (1992) Ideological diversity and government survival in Western European parliamentary democracies. Comparative Political Studies 25: 332-361.

Warwick P (1996) Coalition government membership in West European parliamentary democracies. British Journal of Political Science 26: 471-99. 